\title{
Designing an Indonesian Leadership Training Program: Reflections upon Decisions Made
}

\author{
Alison Atwell \\ University of Southern Queensland, Toowoomba, Australia
}

\author{
alison.atwell@centrin.net.id
}

\begin{abstract}
Doctoral research offers a unique opportunity to implement a carefully planned research design. In undertaking a doctoral research project that sought to investigate the impact of a leadership program in three impoverished rural school communities in Central Lombok, Indonesia, it was essential to consider a range of design elements. It was necessary to ensure design elements that would both support successful leadership training and sit comfortably within the context of the local community and the wider setting of the recently decentralized Indonesian education system. This paper explores the nature of the design decisions that evolved in undertaking research to gauge the changes in leadership perceptions and the dynamics of school operations when leadership training is offered to school communities that are making the transition to school based management under decentralization. It reviews the impact of those decisions and discusses their initial implications within the research context.
\end{abstract}

Keywords: research design, school leadership, reflective practice, cultural context.

\section{Introduction}

Merriam (1998) suggests that planning a research project has similarities to planning a yearly vacation trip. Before embarking on any vacation much thought must be given to factors such as the destination, the cost, the method of travel, and the length of stay. These same decisions apply to undertaking a research project. In June 2004 I commenced a doctoral research project in Central Lombok, East Indonesia to explore issues of school leadership within three impoverished rural school communities. From the outset this was designed as qualitative research, which was intended to explore the meaning, to understand the manner in which a specific group of individuals had constructed their world and the way in which they related within their social setting. Gillham (2004) notes that qualitative methods are designed to generate evidence that extracts meaning from events as they unfold.

The research conducted considered what changes occur within school communities when they are offered an initial leadership training program followed by a six month supported period of prac-

Material published as part of this journal, either on-line or in print, is copyrighted by the Informing Science Institute. Permission to make digital or paper copy of part or all of these works for personal or classroom use is granted without fee provided that the copies are not made or distributed for profit or commercial advantage AND that copies 1) bear this notice in full and 2) give the full citation on the first page. It is permissible to abstract these works so long as credit is given. To copy in all other cases or to republish or to post on a server or to redistribute to lists requires specific permission and payment of a fee. Contact Publisher@InformingScience.org to request redistribution permission. tice within the school and community environment. In particular it considered what changes occur in the perceptions of leadership for teachers, principals and school community members. It also considered how such changes impacted on the dynamics of school operations within the school community. The research reflected on how experiencing a distributed shared model of leadership would impact 
upon the manner in which school community stakeholders carry out their roles within a newly decentralized education system.

Indonesia formally decentralized education through Indonesian Law 22/1999 and Government Regulation No. 25/2000 in January 2001 (Jalal \& Mustafa, 2001). Within any decentralized system there is a strong need for leadership at a local level so that communities may thrive through self-management. However Indonesia is still moving through a difficult transition stage: "Indonesia is having to face the growing pains associated with this national learning process ... paternalistic behaviour left over from centuries of centralistic policy making on the one hand, and the extreme dependency of some areas, on the other, can be hard to change simply by edict" (The World Bank, 2005, p. xi). Aid projects are a primary means of introducing educational reforms and significant educational concepts throughout Indonesia. While many Aid projects within Indonesia address the issues of school based management in general, they do not provide specific input to assist school communities in embracing the necessary change from the top down leadership style of the centralized system to the shared or distributed style of leadership required within a decentralized system. Thus this research gauged what form leadership training could take in the future as an inclusion in Aid projects.

Indonesia has a population of more than 215 million people. Indonesian education therefore serves an enormous school population, estimated at 25,400,000 persons (Muslim, 2002). Since decentralization Indonesia has tried to increase its education budget. In the late 1990s Indonesia was ranked as having the lowest spending amongst its Asian neighbours "with just $1.4 \%$ of its GDP on education in comparison to $4.7 \%$ in Thailand and $4.6 \%$ in Malaysia" (The World Bank, 2005 , p. 18). However the Government of Indonesia's 2006 budget allows an allocation of less than $10 \%$ of total spending to education, well below the $20 \%$ originally mandated in the constitution of 1945 (Hudiono, 2005). What this means in terms of education throughout the country is that even the most basic resources are scarce and in many cases below standard or non existent as noted in The World Bank (2003) report; "In poor and disadvantaged areas, too many schools are badly in need of repair; too many teachers do not meet the minimum qualification for teaching, and too many are not motivated to do their best in the class-room" (p.64). Thus any funding to actually improve educational practice is frequently reliant on the assistance of Aid agencies. This research in attaching itself to such an Aid project was therefore intended to contribute to future educational practice within Indonesia.

The research culminated in case studies of each of the three rural Lombok schools to enable a cross-case analysis to inform a report on the changes in school dynamics in relation to school based management within a decentralized system. At the conclusion of the research this report will be presented to Indonesian Ministry of National Education officials as well as key stakeholders in Aid organizations with recommendations for future leadership training programs. This paper specifically considers the design phase of the research, focusing on issues that were crucial in authentically informing the writing of the case studies and thus the recommendations offered for future educational practice in terms of leadership training programs to the Ministry of National Education.

In following a qualitative research method, the Lombok research looked at the uniqueness of one particular context from the participants' perspective and considered what interactions actually took place there. It was intended to gain depth of understanding of three schools undertaking a leadership training program, rather than to be a broad view of leadership in general within Indonesian education. This paper therefore explores how such a qualitative research design was achieved, examining its specific framework for action. Patton (2002) believes that a wellconceived strategy offers a sense of direction and therefore provides a framework for decisionmaking and action permitting seemingly isolated tasks and activities to integrate towards a common purpose. The paper reviews what design considerations had to be made in ensuring that an 
insider's perspective of the situation in these three Lombok schools was accomplished. It considers the selection of schools and participants, the style of the leadership program and reflective activities offered, set within an understanding of Lombok culture and its educational context.

The design of this project aimed at ensuring that a variety of factors were heeded, such as the involvement of all school community stakeholders, an understanding of local traditions and attitudes towards gender and religion, and the specific training needs required in that Central Lombok is still primarily an oral society. Throughout the project there continued to be a very practical orientation as the intention was to enhance leadership skills within school communities rather than to simply measure existing skills. This enhancement was provided in the form of an initial live-in workshop, review and discussion sessions on a six weekly basis, weekly writing of reflective journals, ongoing professional development through suitable leadership texts, and a network meeting six weeks prior to the project's conclusion. It was intended to capture the findings of the analysed data in the form of case studies as this was seen as an authentic method of presenting the essence of the leadership experience at each of the three schools. As Yin (2003) notes, "The case study method allows investigators to retain the holistic and meaningful characteristics of real-life events" (p.2).

\section{Reviewing Relevant Literature for Design Decisions}

When any journey is to be undertaken it proves a valuable exercise to consider those who have travelled similar pathways before. While a researcher may be branching off the established pathway to explore new directions there is still much to be gained from having a solid understanding of the terrain. As Schostak (2002) notes, "Entering a new city, it helps having a map or a local person as a guide. Doing research means forever having to find ways of getting your bearings" (p. 10). Thus a brief overview of literature that offers insight in relation to four broad areas, which are pertinent to this current research, provides a good starting point to gain bearings. Relevant literature was reviewed in relation to making effective sampling decisions, choosing an appropriate style of leadership training program, gauging relevant tools for participant reflection and determining the impact of local and educational context.

\section{Sampling}

Wiersma (2000) states, "The logic of purposeful sampling is based on a sample of informationrich cases studied in depth. There is no assumption that all members of the population are equivalent data sources" (p.285). Miles and Huberman (1994) believe that the tendency for purposeful sampling to be more commonly used with qualitative research may be attributed to the fact that qualitative research considers a more defined segment of the universe and that in addition the social processes, which are frequently under investigation have a sense of logic and coherence that "random sampling can reduce to uninterpretable sawdust" (p.27). In making choices related to sampling, Yin (2003) suggests that one must clearly look at what the final desired outcomes of the research warrant. Thus when a case study presentation is envisaged one must take into consideration a form of sampling that allows for a multiple case study approach rather than a single case study approach as this will prove conducive to the long term results, "Single case designs are vulnerable if only because you will have put 'all your eggs in one basket'. More important, the analytic benefits from having two (or more) cases may be substantial" (Yin, 2003, p53).

Kvale (1996), in discussing the number of subjects that is appropriate for any one study, suggests that when interviews are used as the basis of the research process, the number of participants tend to be around fifteen plus or minus ten. Seidman (1998) claims that decisions made in relation to how many participants to include in a study rest on two criteria. The first is sufficiency, in terms of whether there are sufficient numbers to reflect the range of participants and sites, which make up the population. This is not for the purpose of generalizability of findings but rather so that oth- 
ers outside the sample might have a chance to connect to the experience of those within the sample. Seidman's second criterion involves saturation of information, the ability of the researcher to reach that point where she is aware that she is totally immersed in sufficient information.

\section{Choosing an Appropriate Style of Leadership Program}

McCollum (1999) writes that effective leadership programs should consider developing the leader from within each person so that a personal development style for the training becomes optimal. This thought is echoed by Woolfe (2002) who claims that leaders do not simply appear but must be consistently and conscientiously developed. Mellahi (2000) takes this one step further in relation to training programs in Asian countries where the norm in the past has been towards an authoritative leadership style, suggesting that such leadership programs must factor in personal development, which assists the participant in dealing with significant behavioural change. This concept is also reinforced by Bezzina (2000) who claims that it is crucial in offering programs to assist participants in their move from a mode of sole leadership towards participative leadership, to help break down former behavioural patterns.

Pounder (2003) provides an overview of what might be considered to be an optimum list for such leadership development, saying that it is hoped that instructors will stimulate participants intellectually, motivate participants to be thoroughly engaged in the process and encourage participants to feel comfortable with both the style of the program being offered and the method or process of its implementation so that as a result participants will have the necessary tools to tackle real life problems in the future. In order to maximise such a transfer of skills following a leadership training program back into the work environment, Myrsiades (2001) points out that action learning projects can become a valuable tool. She believes that by doing so support for common goals is fostered, which serves to create a shared mindset amongst participants, binding them together in a common purpose at their worksite. When deciding on an appropriate training program for leadership development, Sugarno (2004) believes that it is not enough to merely offer this through traditional training techniques, which in the main simply provide a theoretical perspective. He suggests a move away from the lecture style format with lengthy overviews of leadership styles and leadership theories towards a more dynamic approach, which is learner centred involving the participants in active engagement such as role-play exercises.

\section{Gauging Appropriate Reflective Activities}

Densten and Gray (2001) believe that the extent to which reflective activities are included within a leadership-training program will have a direct impact upon the effectiveness of such programs. Langer (2002) states that a reflective journal can provide a valuable tool for use in training programs. Haigh (2001), in supporting the use of such journals, writes, "They make students self conscious of their learning and encourage the learner to reflect on what is being learnt and how" (p.168). It is Rosier's belief (2002) that when participants write a reflective report of their experiences, this improves the writer's perceptions of values and relevance, which in turn serves to encourage the transfer of learning from a theoretical sphere directly into the workplace. Loo and Thorpe (2002) speak of the empowering side effect of journal writing. They see this writing process as an opportunity for learners to take a good deal of control over their individual learning experiences and thus to give personalised meaning to their learning. In this way they see journal writing as a significant tool for translating theory into practical action. Cacioppe (1998) notes that through this empowering experience of journal writing the participant is more likely to continue developing as the journal offers a successful means of self-evaluation.

In terms of such self evaluation Gorman (1998) believes that when school staff are involved in the practice of reflective writing through journals that the journal can actually work as a pseudo 'master teacher' watching over the practitioner, continually questioning the methods that are be- 
ing used and discovering a range of strengths and weaknesses. It is Morrison's view (1996) that the use of such a journal offers multiple benefits. These include charting experiences, recording a developing dialogue between academic, personal and professional spheres and developing the ability to engage in reflective practice. In this way participants become self-aware, which in turn enhances their sense of self-empowerment. O'Rourke (1998) claims that journal writing encourages the development of critical reflection linked to professional practice. O'Rourke believes that a journal becomes a powerful tool for developing confidence by making use of new concepts when the learning process becomes embedded in real practice, as it involves a constant move between the subjective, the particular and the general.

\section{Considering Local Context}

Alavi and McCormick (2004) state that a school's culture can be highly influenced by the societal culture or community in which it sits. McGinty (2002) suggests that schools take the form of community assets and that the schools are then in turn well placed to assist in building capacity for the entire community. She believes that leadership in such a community becomes the ability to represent the interest of all stakeholders in a manner that has them all working together to achieve the sustainable vision and strategic direction of the community as a whole. Mason (2000) defines the fundamental essence of community as referring to groups whose members share values and a way of life, identify with the group and the practices of that group and openly acknowledge each other as members. Jason (1997) writes that community implies that people share a "common mission, connectedness and reciprocal responsibility" (p.75). This provides them with a sense of safety to share vulnerabilities and sadness as well as their sense of joy. Waddock (1999) also views community as involving a sense of connectedness and a healthy sense of interdependence in an environment that offers caring, belonging and a sense of trust so that individuals work together in a joint enterprise, which is bigger than any one person and is built upon principles of collaboration rather than competition.

In considering how community is defined, Burdett (1998) claims that the very first aspect that denotes community is how a group states and frames its mission. He says that this needs to inspire and value add for all stakeholders so that the community will be grounded not just in the present but also through honouring its specific past. Waddock (1999) goes one step further to suggest that community involves spirituality as it encompasses those aspects of life that are internalised and expressive as opposed to those that are externalised and more measurable in a concrete sense. Miller (2002) takes the concept of spirituality to another dimension when he frames it in the context of faith communities where people are drawn together by shared religion. Miller claims that such communities spend significant amounts of time together daily in prayer and dayto-day aspects of their religion, causing them to be strongly bonded by elements of their faith.

\section{The Research Design for the Journey}

In order to determine the extent to which the design of this research project succeeded in probing the worlds of the fifteen participants so that authentic and meaningful case studies could be achieved, Schostak's premise regarding "experiences of reality" is utilized. In 2002 Schostak wrote that:

A qualitative research project explores the ways through which a 'self' and its 'world' are constituted through an imaginative grasp in relation to experiences of 'Reality'. What 'ties' them together are the intricate web of purposes, motives, interests, needs, demands, feelings and so on structured by the language we use to express ourselves to others and by which we orient our behaviour with theirs and they with us in a world of material structures. (p.18) 
Thus this paper explores five different "experiences of reality" considered within the design process in an effort to gauge whether this relationship between "self" and "world" has been illuminated. It looks at why decisions were made about such "experiences of reality" and subsequently explores the manner in which these Lombok school communities were served through this leadership-training program.

\section{Experience of Reality One: Selection of Schools and Participants}

While sampling is fundamental to all research design, decisions made are often complex and the Lombok project sampling required consideration of a range of factors. Three schools were chosen to participate in this project. It was considered important to select schools that were already attached to a broader Aid project, given that so much funding for both physical rehabilitation of schools and professional enhancement of teaching and learning practices within Indonesia is sourced via donor projects from a range of countries. It was considered that if this project proved effective then the possibility of attaching a similar program to future Aid projects might be realized. A Japan Fund for Poverty Reduction (JFPR) project operating across fifty-seven schools below the poverty line in Eastern Indonesia was therefore selected. The JFPR project was seen as being relevant in that it specifically targeted issues related to decentralization of schooling. However at the same time it did not address issues of leadership.

To determine which three of the fifty-seven schools would be involved, it was decided to use primary schools rather than a mixture of primary and secondary so that there would be a common thread of meaning for discussion. Primary schools were chosen, as there are thirty-seven government primary schools and eleven madrasah or Islamic primary schools amongst the fifty-seven JFPR schools. High schools formed a minority in the JFPR project with only two government high schools and seven Islamic junior high schools. Schools were further selected in relation to which of the fifty-seven schools had actively indicated an interest in further professional development. In addition the proximity of the three schools to each other as well as their accessibility during the wet season was also considered.

The final choice involved two government primary schools and one madrasah. Each school was then given a colour-coded name, Sekolah Merah or the Red School, Sekolah Hijau or the Green School and Sekolah Biru or the Blue School, in order to ensure confidentiality of data. In choosing the actual participants the choice is often between "a narrow range of experiences for a larger number of people or a broader range of experience for a smaller number of people" (Patton, 2002, p.227). A tangible "experience of reality" for this research study was seen as seeking to work with a "smaller number of people". Thus five participants were chosen from each of the three schools to include in each case the principal, two teachers and two members of the School Committee. Each school selected its own group of five after the principal was briefed regarding the research. While the desire for gender balance was stressed, the final group included five women and ten men, with one female principal, two female teachers and two female School Committee members. All participants were practicing Muslims living communal lives within a 200 metre radius of their school with the exception of one contract teacher who lived two kilometres from her school.

\section{Experience of Reality Two: Style of Leadership Program}

Lambert (2003) states that, "How we define leadership frames how people will participate in it" (p.4). Thus as a genuine "experience of reality" the scaffolding of the leadership program to be presented to the fifteen participants proved to be an all important design decision. Following initial interviews at the three schools to gauge levels of awareness and understanding in relation to leadership issues, a two-day live-in workshop was organised to bring all fifteen participants together. The workshop was designed to model the Pembelajaran Aktif Kreatif Efektif dan Menye- 
nangkan (PAKEM) program, which offers an interactive, participative approach. PAKEM translates as Active Creative Effective and Joyful Learning. (UNESCO-UNICEF, 2003, p. 4). The PAKEM program is part of the JFPR method of delivery, and all three schools had previously been to socialization workshops for PAKEM. Thus the delivery of the workshop involved group work, role-plays, problem solving, etc., set within a context of vividly displayed resources and wall charts of completed work. In addition given the oral tradition of the Lombok culture, a variety of storytelling was utilized throughout the two days to include enriching costumed dramatizations of local legends by each of the three schools. The workshop covered a broad spectrum of leadership concepts from theory to the creation of personalised definitions. Throughout the workshop the primary focus was on shared leadership. The workshop design included the formulation of a school-based project by each of the three schools, which necessitated the trialling and practice of leadership skills across the following six months.

\section{Experience of Reality Three: Range of Reflective Activities}

Individuals determine their reality through reflecting upon it via a range of measures. Journals were chosen as a writing tool to monitor and self evaluate the process of learning for each participant across the six-month period following the workshop. The journal entries were completed on a weekly basis and formatted to include questions that related both to a chronicling of leadership activities and reflection upon the practice of leadership skills. In addition my return to site each five to six weeks offered a further reflective tool in the ensuing discussions, which became part of these visits. Each school was also provided with a basic camera and a film supply to keep a visual monitoring of their six months. Completed films were developed and returned to each school and replacement films provided. One month prior to the completion of the research, a network meeting was held with all three schools present engaged in presenting results of projects and further expanding their views on leadership.

\section{Experience of Reality Four: Understanding Lombok Culture}

Each school selected was situated within a central Lombok village community. The society of Central Lombok is decidedly traditional. This is the home of the Sasak people who live a communal village life. According to Smith (1997) modern technology has barely affected Lombok so that traditions remain on the whole virtually untainted, with cultural ceremonies not merely geared to tourists but rather genuine expressions in their own right. Thus in undertaking this research this understanding of 'reality', the ebbs and flows of the participants' village existences, was crucial in terms of designing an appropriate form for the study. The three schools are placed within a rural setting within a five kilometres radius. The majority of parents in all three schools work on farms either as labourers or on their own smallholdings. The horse and cart is the preferred means of local transport as roads are frequently in need of repair. Sasak is the first language spoken locally although children are introduced to the Indonesian language during the initial years of schooling. Traditional law is still paramount in the area in which the three schools are to be found, particularly in relation to the significant ceremonies surrounding births, marriages and deaths.

All three schools were firmly connected to their Islamic communities. All participants were practicing Muslims with all five female participants following Islamic dress codes. Each school was involved with community activities at their local mosque and the madrasah, Sekolah Hijau, converted one large classroom into an additional "little mosque" for the community during the month of Ramadhan. All schools reduced their academic programs during the Ramadhan month focussing rather on prayers and recital of the Koran. Central Lombok society encourages the early marriage of females so that many girls wed by age fourteen causing high drop out rates in early high school years. When family finances are poor, the male is sent to school in preference to the fe- 
male so that the retention rate for males is considerably higher. Women are under represented in areas such as School Committees. The three schools had a total of twenty-eight School Committee members. Only four of these Committee members were females. It is considered inappropriate for a female to voice her opinion in a public forum. The three schools had a total of thirty-one teaching staff, with twenty-one males and ten females.

\section{Experience of Reality Five: Consideration of Educational Context}

The three schools involved in the research are all living examples of schooling issues throughout Indonesia and rural Indonesia in particular. Their "experience of reality" is a daily experience of making do with few resources and poor physical conditions. The World Bank (2003) report on Indonesian education points out that:

Large inequalities in education remain among income groups and between rural and urban populations. These inequalities are striking, especially in terms of the quality of the schools that young people attend. In poor and disadvantaged areas, too many schools are badly in need of repair; too many teachers do not meet the minimum qualification for teaching and too many are not motivated to do their best in the classroom. (p.64)

There is a variation in the three schools in relation to teaching staff. At Sekolah Merah all ten teachers are paid government workers and both teacher representatives for the research hold two year teaching diplomas. At Sekolah Hijau however, ten of the eleven staff are honorary teachers who receive no salary for their work. The two teacher representatives from Sekolah Hijau completed senior high school but have no further qualifications. At Sekolah Biru two of the eight teachers are honorary and both teacher representatives have a two year teaching diploma. All three schools have recently received financial input from the JFPR project to rehabilitate school buildings. In each case however classroom conditions are still very basic with poorly lit classrooms. Each school suffers from a lack of water so that yards are dusty and non conducive to playground activity. Sanitation is an issue in all three schools. Whereas Sekolah Merah and Sekolah Biru teach a full government curriculum, Sekolah Hijau, as a madrasah, teaches a curriculum that is $70 \%$ government and $30 \%$ religious.

Indonesia advocates a policy of Nine Years Basic Education. Currently the attendance rate for classes one through to six in the area in Lombok in which the research is situated is $79.6 \%$, although this falls during the three compulsory years of junior high school to $40.5 \%$ with only $37.5 \%$ of all females in this area completing their nine compulsory years of education (SAGRIC, 2003 , p.2). Although Indonesian education moved to a decentralized model in 2001, the impact of decentralization has frequently been questioned; "Policy making has traditionally been a central government function, and the tendency is still to devise central frameworks for local application, rather than national frameworks built from broad-based local consensus" (Mukherjee, Hardjono \& Carriere, 2002, p.1).

\section{Analysing the Design Decisions: Melding Strategies with Outcomes}

In Schostak's premise for qualitative research, these "experiences of reality" should offer a way to explore the connections between "self" and "world". In this research project this could only occur if the "experiences of reality" had been wisely considered within the research design. Thus it is worthwhile to review initial outcomes of the research to evaluate whether the design was well "tied together". The final results of this research will be presented as a concept paper to the Indonesian Ministry of National Education with the hope of creating a working model where future 
leadership training programs may be attached to Aid projects throughout Indonesia. For such a model to be valid it is imperative that it be effectively scaffolded within the 'experiences of reality' of Indonesian educational culture so that transference is not an issue.

\section{Selection of Schools and Participants: The Impact of Design Decisions Made}

Essentially choosing schools that were all proactive in desiring further professional development meant that each of the three schools was keen to gain new skills via the program. This was noted through eager participation at the weekend workshop, continuing circulation of the leadership texts, which were offered on loan to the three schools, attendance for further discussion during the six weekly visits, completion of weekly journal writing, attendance at the network meeting held at the five month mark, commitment to keeping a photographic record, and eagerness to take part in the final interviewing session. Choosing schools that would prove accessible during Lombok's wet season allowed for visits to each of the three schools regardless of the season. Localized flooding meant that a number of other JFPR schools proved unable to be reached in the wet season. The selection of primary schools did ensure that all three schools were able to discuss common interests such as PAKEM concepts, retention concerns, assessment procedures and school uniform dilemmas during group activities at the workshop and network meeting. This also provided a further sense of immediacy to the projects undertaken and the successes achieved during the six month period, as the schools felt as if they were on an equal playing field.

In attaching the research to an ongoing Aid project a number of outcomes were realized. All three schools were eager to build upon gains made through the input from the JFPR project. Having classrooms that were freshly painted with repaired walls and ceilings meant that participants were interested in practising new skills gained via the leadership training program and keen to model the PAKEM concepts. Similarly the JFPR project, while it offered no training in leadership, certainly placed change upon the agenda for these three schools. The new leadership practices gained via the weekend workshop and later through the ongoing activities underlined a need for change in a move from a model of individual leadership towards a model that encouraged shared leadership.

Choosing five personnel to represent each school provided a solid core group as an ongoing working party on leadership in each school. The balance of participants within each group of five proved indicative of the dynamics within the wider school community. It was of course essential to have the principal from each school participating, but providing, also, an equal representation of teachers and School Committee representatives proved valid in terms of school influence. In each school the School Committee was heralded as a significant force in terms of school operation. During discussions and interviews mention was made of how the predecessor to the School Committee, the School Board, was a group in name only, which had little to do with the ongoing running of the school community. In addition the breakdown of the fifteen participants meant that during workshop activities, when it was considered worthwhile to divide groups according to roles, that a group of three principals, one of six teachers and one of six community members provided suitable working groups. While only five of the fifteen participants were women, this did offer an opportunity to concentrate on this smaller group to ensure that the women's opinions and needs were heard. It also provided an active example of the degree to which women are under-represented in schooling and continually reinforced the necessity of acting upon this. 


\section{Style of Leadership Program: The Impact of Design Decisions Made}

A two day live-in leadership workshop program was chosen as being the best possible means of delivering the wide range of learning activities that would offer a solid foundation for new skills and a new understanding of leadership. It was considered that taking the fifteen participants out of their local rural environment to a workshop venue, approximately one and a half hour's drive from their village homes, would offer a stark contrast to heighten the intention of making changes. A weekend was chosen, as Saturday schooling is a shorter day so that teacher release back at the schools was less problematic and, of course, Sunday is a day free from standard school commitments. A longer workshop was not a possibility in terms of both the cost of staff release from schools and the commitment of participants to village life. The majority of these participants have second jobs. In many cases the second job, as with three of the participants from Sekolah Hijau, provides the only income. All participants look to ways of gaining income through activities outside their school or workplace, as wages are insufficient to meet living requirements.

Making use of the PAKEM method throughout the training workshop proved invaluable. Although many of the participants had previously attended local workshops all reported that they had not before experienced a workshop where they were constantly involved in the process through games, role plays, group work, story telling, etc. Displaying theories and pertinent points around the walls on brightly coloured cardboard did entice many of the participants to actively read, which is not common within Lombok culture. The use of story telling as a tool also proved advantageous. In an oral culture such as this being able to spin a good yarn to teach a point or heighten awareness is seen as a necessary skill, so, in drawing upon this method, a statement of recognition of local custom was being made, while at the same time benefits were being gained through the expertise of the story telling.

The style of leadership, which was emphasised throughout the workshop, was that of shared leadership, and the participants were constantly required to model this in all activities undertaken, as well as having it reinforced through the materials provided both in an oral and written form. The broad range of leadership definitions and theories presented offered a solid bank of possibilities for participants to digest and draw upon in the future. The workshop included synthesising activities, such as the personalised definitions of a leader and of leadership produced by each of the three schools. This in effect meant that each school returned from the workshop with two framed statements, which were then proudly displayed in their school staff rooms. One bore the words, "At School X we believe a leader is. .." and the other stated, "At School X we believe leadership is about ..." In both cases the actual school's name was entered on the statement as these statements were being publicly displayed. It was, therefore, not considered necessary to use the colour coded school names. These framed pieces proved ongoing powerful reminders for the schools of the meaning they were now attributing to leadership.

On the final day of the workshop each school was asked to devise a school based project that would have the dual benefit of enhancing school quality while at the same time providing a vehicle for practicing new leadership skills. The resulting projects all focussed on aspects of school enhancement that centred on the physical well-being of students. This was either in the form of work that would physically improve their schools, such as paving playgrounds, constructing flower beds, badminton courts and outdoor seating, or work that involved the creation of school programs for nail care and general cleanliness. While these school based activities across a six month time span were crucial to the workshop design, in addition the workshop encouraged each participant to practice leadership skills in all aspects of life, whether this was in family circles, work environments or community activities. 
The journals, which were kept individually each week, chronicled over one hundred different activities itemised by the fifteen participants as being opportunities to practice leadership skills. While many of these were at school, such as leadership in the provision of new school drainage, leadership in beginning a medicinal herb project, and leadership in restructuring rooms to follow PAKEM concepts, other activities were family based. These included family leadership involved in coming to terms with poor family finances and leadership in determining a pattern of management for the family rice paddy. Community based leadership activities varied from working together with others for a villager's funeral arrangements, starting up a children's playgroup, operating a village cooperative, arranging weekly Koran readings, and preparing Idul Fitri celebra-

tions. Participants also took their newly acquired leadership activities into a range of work related venues to practice their skills and reported challenges in leading village disputes over land rights, in starting up a local cooperative, in mediating tax collection, and in commencing a profit sharing school canteen. All fifteen participants stated during the final interview session that they would consider the leadership training program to be valuable for other schools to experience and stressed the need for a similar strategy in terms of the combination of workshop, journals, site visits and network meetings. In summing up one School Committee participant stated, "the sooner the better that there is this kind of program for other schools." (Comment by head of School Committee at Sekolah Merah, February 5, 2005).

\section{Range of Reflective Activities: The Impact of Design Decisions Made}

Journal writing was chosen as a tool to capture the journey of each of the fifteen participants during the six-month period between the initial workshop and the concluding interviews. Regular writing is not a common practice amongst school staff or local community members. However, the possible benefits were seen as outweighing the potential risks, and steps were put in place to minimize any problems that might occur. During the final session of the workshop, after an overview was delivered on the procedures for journal writing, each participant was given the opportunity to make the first journal entry in their loose leafed journal, which was provided for them, and then to discuss any issues that evolved in this process. Participants were encouraged to enhance the written word through the addition of poetry, drawings, or photographs. During each six weekly visit to the schools the new journal entries were collected for copying and translation, and any arising issues were discussed in detail.

Although individuals did not always record a weekly entry, one participant at Sekolah Hijau chose to write additional entries. For this reason in the final analysis Sekolah Hijau had a 104\% return on journal entries, Sekolah Merah a $98.4 \%$ return, and Sekolah Biru an $83.2 \%$ return, giving an average return of $95.2 \%$ across the three schools. There was a broad variation in the journal writing with some of the seven structured questions being answered in detail by some participants and some questions eliciting a brief response. In the final interviews with each of the fifteen participants all participants were enthusiastic as to the value of the journal, and the majority of participants stated that they would personally choose to use a journal for reflective purposes in the future. The journals, above all, gave the participants a tool in measuring the extent of their own growth. Participants spoke of how they believed it offered them personal accountability for their own actions, "The journal has helped me remember what I have done and to learn the weaknesses and strengths of a particular program and then to do better next time" (Comment by member of School Committee at Sekolah Hijau, February 6, 2005).

Photographing leadership activities in which the school was involved provided each school with a visual record of their six months, which offered concrete proof that they were in fact trialling new ideas. This had an impact within their local communities as photos were displayed of activities that could otherwise not be seen by parents and community members. These photos from inex- 
pensive cameras became a powerful tool in connecting school and community, and all participants spoke in positive terms of the use of the photographs during the final interviews. I returned to site each six weeks to discuss leadership issues and attend to the journals and films. Participants unanimously agreed that these visits were essential in terms of sifting through new issues, building on skills, and providing a source of motivation for the ensuing weeks. The School Committee member from Sekolah Hijau summed these visits up as being important to "monitor and motivate" (Comment by head of School Committee at Sekolah Hijau, February 6, 2005). These sessions frequently involved all five participants from each school, with the School Committee representatives arranging to reschedule work to be present and teachers reorganising their classes to allow them to participate. A striking factor of these informal gatherings was that there was a great sense of sharing and evidence of partnerships occurring at each school. The principal didn't attempt to dominate these sessions, and the women spoke freely without any fears of being sanctioned.

\section{Understanding Lombok Culture: The Impact of Design Decisions Made}

Acknowledging that religion was central to each of the fifteen participant's worlds meant encouraging each one to practise any leadership skills gained in many aspects of their lives within their local religious community. Thus journals recorded how such skills were employed when teaching the Koran, organising local youth to be involved in weekly sessions to clean the mosque, arranging programs for Idul Fitri, etc. In addition, in writing the workshop program it was important to consider an agenda that would allow for sufficient time for prayer breaks as well as to ensure that all meals provided were strictly halal (food prepared according to Muslim law). At the school level, visits to the sites during the month of Ramadhan were negotiated at suitable times as all schools were on alternative programs to allow for both active participation in prayers and Koran lessons as well as to support the staff and children at this time of fasting. At all times strict deference was adhered to in terms of dress codes and Islamic custom when meeting with the participants.

There was a constant awareness of the need to ensure that the female participants were included in all aspects of the research. Throughout the workshop sessions they were actively encouraged to have a voice and after initial shyness all five rose to this challenge. Despite her successful leadership within Sekolah Merah, the principal prefaced comments during the final interview when discussing the results of Sekolah Merah's school based project by saying, "I am a female so I don't know everything" (Comment by principal at Sekolah Merah, February 5, 2005). The community representative from Sekolah Biru, as the only female on the School Committee, related that she was never able to express her opinion at meetings as she was told that she was "just a woman". Following the workshop her answer to this admonishment was simply to seek new ways to express her new leadership skills so that she established a profit share canteen at the school using money that she made from expanding her small sewing business. In the final interview she stated that she was simply not going to listen to such comments about her gender and that the program had taught her instead to be calmly proactive in trialling her leadership skills." I have to be strong and I believe in my heart. I don't care so much about what people say and on top of that I have support from my husband and family" (Comment by member of School Committee at Sekolah Biru, February 7, 2005).

An understanding of the strong traditions of this society highlighted the need to work within the participants' framework, celebrating their local legends via storytelling at the workshop, making use of local Sasak building customs to illustrate differences between leadership and management, and focussing on relevant local themes for role plays and problem solving sessions. At site visits and again in journals leadership skills practiced within their own specific ceremonies for births, 
deaths and marriages were all openly discussed, as were practices involved with rice distribution to the poor, organizing visits to sacred grave sites, mediation in local inheritance disputes. and village cooperative efforts to rebuild neighbours' homes hit by an earthquake. It was recognized that the participants lived in close proximity to their schools. Anything beyond 200 metres from the school gate was labelled as "far" in terms of distance. This was seen as indicative of their close relationships with all in the school community and those in the broader village community. In final interviews participants all reported the growth of strong community links and a complementary relationship between school and village communities. Whereas the village community would be on hand to assist with school rehabilitation projects, the school community would in return be there to help rebuild the village mosque.

\section{Consideration of Educational Context: The Impact of Design Decisions Made}

From the commencement of this research project it was reinforced to the participants that the program would be value adding in terms of professional development but would not in any way be able to financially assist the schools through donations of money or goods to support the learning. This was seen as crucial as, given the impoverished state of the educational facilities, there was an awareness that money may be required to acquire fundamental materials both inside the classroom and in schoolyards when projects to follow through with leadership skills were undertaken. In making this emphatic from the beginning the schools were, thereby, encouraged to fall back on their own resources to raise any needed funds as well as to source leadership activities that didn't require any outlay. Thus Sekolah Hijau organised a one day hike to nearby Mount Sasak, which involved one hundred of its school community members, Sekolah Biru started a Scouting Group and went on its first overnight camp with two tents bought through a separate school endeavour, and Sekolah Merah cleverly chose the harvest season, when there was a little more money in the local community, to raise funds for the paving exercise.

In writing the workshop program the educational backgrounds of both the teachers and the community representatives were taken into consideration. Six of the fifteen participants had not undertaken formal study since leaving high school while one community representative had left school at fourteen to marry, so had only a junior high school education. Thus a variance in the ability to comprehend written concepts was prevalent and a need to offer oral explanations in practical terms with avoidance of any overuse of technical terms was essential. Understanding that there were unpaid teachers within the group, as well as realising that those who were paid still required second incomes to survive, meant acknowledging that any formal training sessions or personal practice of leadership concepts must fit in around already busy lives. This again stressed the importance of trialling leadership skills in the home and community as well as in the school environment.

Each of the three schools was seen to be actively working with the School Committees, which have become mandatory since decentralization, and at the time of the research the schools were eager to source new methods for applying leadership in this area. Under the previous centralized system, leadership had very much been the domain of the principal, and several participants stated during the final interview sessions that they had now moved beyond seeing leadership in terms of a one-person show in their schools. All fifteen individually responded in answer to questions about whom they currently saw as leaders in their schools with a list that included the principal, the teachers, the school committee, and the students. At all three schools the claim was made that the school was now working very closely in cooperation with the School Committee as the leadership training had provided the skills to facilitate this process. 


\section{Conclusions Drawn}

In the final analysis the only relevant question is whether the design decisions made accomplished their intended purpose. The research design of this project was intended to work systematically at viewing just how "self" and "world" were constituted in relation to a range of "experiences of reality" so that a deeper understanding of the meaning given to this six-month leadership training could be achieved. From the very beginning of undertaking a qualitative research project, choices made in relation to the research design have ongoing implications throughout the duration of the project and then further into the analysis and writing phases as they hold the key to bringing the world of the participants to life. In the end they become the connecting thread, which will ensure that the research context can be later felt and lived, shared and above all celebrated by others.

\section{Sampling}

Because the fifteen participants in this research proved dedicated to the process to which they had voluntarily committed, there was an opportunity to gain rich insight into their daily experiences and to connect leadership practices across the full spectrum of their worlds. The decision to employ purposeful sampling proved to have dividends as it ensured that by viewing a small group in all its intensity that the valued insights gained were certainly not reduced to "uninterpretable sawdust" (Miles and Huberman, 1994, p.27). By providing rich material from three separate sites, it set the scene for the writing of a multiple set of case studies, which would offer a range of perspectives on the same issues, while at the same time remaining mindful of the need that all insights gleaned from such case studies would be viewed within the specific context of each school site. The initial outcomes do indicate that the choice of a sample for leadership training that is attached to an Aid project provides a viable means of operation as a mutual relationship can be established whereby the leadership training benefits and is positively impacted upon by the larger Aid project. The specific mix of participants succeeded in offering a sense of balance to the research so that the voices of community, teaching staff and principals were all heard. In any future replication of such programs further efforts to balance gender representation could prove advisable.

\section{Style of Leadership Program}

The leadership-training program did take into account the need to support change by developing the leader within each participant and to offer an alternative process for leadership, which was shared and experienced by all. The gains subsequently made in terms of understanding the nature of leadership were therefore significant gains not merely gains that were pigeon holed into only one of life's activities. Nor were gains made seen as being relevant only for the period of the research. Participants spoke not only of incorporating their new understanding into future projects but also of the personal changes, which had been experienced in their world via the leadershiptraining program.

Of primary significance is the movement through the period to extend the boundaries of leadership, to widen their understanding of their leadership world. Thus the participants moved from a singular model of leadership towards a more all-encompassing shared model. The participants thrived on the participative activity centred approach offered initially through the leadership workshop and then later in the project work undertaken at a school level. This method is therefore seen to hold future promise for further leadership training experiences. While the two days utilised for a live in workshop could well be extended in terms of participant's interest and material to be covered, the possibility of removing participants from their school and community life for any more than a weekend is not realistic. The use of both school based projects and personal projects as a vehicle to practice leadership skills proved invaluable for the outcomes of the research. 


\section{Reflective Activities}

Despite being a project of brief duration the built in reinforcements within the project design such as the journal writing and site visits were acknowledged as being related to positive outcomes. Journal writing offered the participants the opportunity to self assess and to monitor their own learning. Furthermore it also proved to make them feel personally accountable for their input at both a school and a community level. There was a sense of control of their own journey through these journals as participants considered that the writing encouraged them to move forward in their chosen direction. Offering a semi-structured journal format proved effective as many of the participants were not used to reflecting on their world and thus they found a weekly scaffold to be extremely useful. Chronicling their leadership growth through systematic photographing had the added benefit of keeping others in their local community abreast of changes, which were occurring at a school level. Site visits during the research phase were also a useful tool in stimulating discussion, ironing out problems as they arose and assisting in keeping the participants connected to their leadership projects.

\section{Local Context}

The design choices have illuminated a range of connections between a variety of aspects of the participants' self and world. There were no boundaries in the lessons learned and practiced between any of the realms of the participants. Their personal, family, school, work and community lives were all seen as legitimate for leadership practice. If projects to be undertaken had been simply restricted to school boundaries much of the enrichment, which occurred in participants lives throughout this research, would not have been given full value. Extreme sensitivity on behalf of the researcher to local customs and values is an important lesson to take on board for any future leadership training programs. In school sites such as these, where faith communities are relevant, it is important to acknowledge the role that religion plays in the participants' lives and encourage learning to be undertaken within their religious sphere as well.

Similarly it is significant to understand that there are distinct limitations surrounding the opportunity to undertake school projects because of the level of poverty experienced in the community. While lack of financial resources did pose issues at a school level, the ingenuity used by many of the participants to overcome this factor provided impressive lessons. While small gains were made throughout the six months in terms of giving females a voice, this also had to be handled sensitively within the context of the local culture to ensure that such gains could be ongoing. Factors such as the closeness of community ties were harnessed wherever possible, as were local methods of learning through oral storytelling. When working within such a community, setting time spent in initial understanding of the cultural context can pay enormous dividends in terms of being able to discern that cultural context.

\section{Indonesian Educational Context}

The schools involved were all poor in terms of resources and readily available funds. Yet the research project managed to move ahead despite this, as the participants were all keen to trial their new skills with or without any money or goods, which might otherwise have proved advantageous. The lesson learned is that it is important to fit into the local educational culture. If this is a situation where people must learn to make do with whatever is available, then this research was successful in showing that entering this environment on the same level on which the participants experience it can be beneficial in terms of encouraging resourcefulness and mirroring the norm. However, the research has also shown that the ground rules must be set out very firmly at the start so that there are no expectations on the part of those involved that schools or participants will be provided with money or resources. The research project did take into consideration the educational background of the participants involved and sought specifically to harness the oral nature 
of the culture in which it was set. This is seen as being a crucial lesson as offering material that is beyond the understanding or reach of some or all of the participants is not a fruitful exercise. It is also important to understand that some of the teachers work in an honorary capacity. This restricted their ability to be involved in additional activities. It was necessary to be sensitive to this aspect and mindful of how new learning experiences could be included in everyday activities. The Indonesian educational culture is moving towards greater inclusiveness in terms of community at school sites, so it was imperative to include community members as major stakeholders in the research process.

\section{Final Comments}

The School Committee representative at Sekolah Hijau reflected upon what he saw as the community's perspective of the results of the leadership training program. This statement in itself highlights the extent to which Sekolah Hijau felt that they had embraced change and moved forward as a school through their leadership training experience. "Yes, I think the community has definitely seen changes in the school leadership, before the school was like dying but not really dead yet" (Comment by head of School Committee at Sekolah Hijau, February 6, 2005). The principal from this school notes, "It was motivation for me. It explained to me about leadership, the true meaning of leadership. Before we had an understanding that leadership was a form of anarchism and then after the workshop I learned that leadership is about cooperation, solving problems together, and not thinking that we are the only one who has the solution to solve problems" (Comment by principal at Sekolah Hijau, February 6, 2005). In effect this principal is affirming that the "experiences of reality", which were considered through the design process have reaped rewards within his life and have led him towards a new and valuable reframing of his own world.

The research design achieved its purpose in offering rich and authentic material to create case studies that highlighted changes in leadership understanding and leadership dynamics that occurred at each of the schools. There was a move from authoritarian, hierarchical leadership to school leadership that was shared, dispersed and open to all stakeholders within the school community. This change in leadership style was seen as being sustainable beyond the time frame of the research project itself. The leadership training program, which provided scaffolding for the research, was seen as being replicable within future Ai projects. The elements of design that were considered crucial to the research, such as an awareness of community context and a need to match style delivery and reflective activity to the participant group, were seen as valued foundations for future programs.

From the outset in designing this research I was constantly aware of my specific status as a researcher. I was both an educational researcher investigating a rural Indonesian school environment and a foreigner entering this environment without a common language or cultural background. Designing research under these circumstances has particular implications for doctoral students embarking on research projects. To achieve dissertation committee support requires a substantive overview of the process and the methodology to allow committee members an understanding of a setting and an educational experience that is unfamiliar to them. Therefore additional preliminary investigations of settings are essential so that the doctoral student has a comprehensive overview of the context in order to inform the committee satisfactorily. It is necessary to allow extra time and funding to do this prior to the proposal being submitted. It is also important to source competent translators and interpreters prior to commencing the research as the design context demands that the researcher enters the participants' environment in an unobtrusive and supportive manner. Above all it is crucial to ensure that all protocols of the country in which the research is being conducted have been followed implicitly. This requires ongoing communication with ministerial bodies and local authorities. Research such as this therefore requires 
commitment, perseverance and a determination to undertake a journey, which will continually prove challenging.

\section{References}

Alavi, S. B. \& McCormick, J. (2004). A cross-cultural analysis of the effectiveness of the learning organizational model in school contexts. The International Journal of Educational Management, 18(7), 408416.

Bezzina, C. (2000). Educational leadership for twenty-first century Malta: Breaking the bonds of dependency. The International Journal of Educational Management, 14(7), 299-307.

Burdett, J. D. (1998). Beyond values: Exploring the twenty-first century organization. Journal of Management Development, 17(1), 27-43.

Cacioppe, R. (1998). An integrated model and approach for the design of effective leadership development programs. Leadership and Organization Development Journal, 19(1), 44-53.

Densten, I. L. \& Gray, J. M. (2001). Leadership development and reflection: What is the connection? The International Journal of Educational Management, 15(3), 119-124.

Gillham, B. (2004). Case study research methods. London: Continuum.

Gorman, D. (1998). Self-tuning teachers: Using reflective journals in writing classes. Journal of Adolescent and Adult Literacy, 41(6), 434-453.

Haigh, M. J. (2001). Constructing Gaia: Using journals to foster reflective learning. Journal of Geography in Higher Education, 25(2), 167-189.

Hudiono, U. (2005, October 29). 2006 budget passed with few snags. The Jakarta Post, p. 1.

Jalal, F. \& Mustafa, B. (Eds.). (2001). Educational reform in the context of regional autonomy: The case of Indonesia. Jakarta: Ministry of National Education and National Development Planning Agency, The Republic of Indonesia.

Jason, L. A. (1997). Community building: Values for a sustainable future. Westport: Praeger.

Kvale, S. (1996). Interviews: An introduction to qualitative research interviewing. Thousand Oaks, CA: Sage Publications.

Lambert, L. (2003). Leadership capacity for lasting school improvement. Alexandria: Association for Supervision and Curriculum Development.

Langer, A. M. (2002). Reflecting on practice: Using learning journals in higher education. Teaching in Higher Education, 7(3), 337-351.

Loo, R., \& Thorpe, K. (2002). Using reflective journals to improve individual and team performance. Team Performance Management: An International Journal, 8(5), 134-139.

Mason, A. (2000). Community, solidarity and belonging: Levels of community and their normative significance. London: Cambridge University Press.

McCollum, B. (1999). Leadership development and self development: An empirical study. Career Development International, 4(3), 149-154.

McGinty, S. (2002). Community capacity building. In P. L. Jeffery (Ed.), Australian Centre for Research in Education Conference 2002. Brisbane: AARE.

Mellahi, K. (2000). The teaching of leadership on UK MBA programmes: A critical analysis from an international perspective. The Journal of Management Development, 19(4), 297-308.

Merriam, S. B. (1998). Qualitative research and case study applications in education. SanFrancisco: Jossey-Bass. 
Miles, M. B. \& Huberman A. M. (1994). Qualitative data analysis (2 ${ }^{\text {nd }}$ ed.). Thousand Oaks, CA: Sage Publications.

Miller, M. (2002). The meaning of community. Social Policy, Summer, 32-36.

Morrison, K. (1996). Developing reflective practice in higher degree students through a learning journal. Studies in Higher Education, 21(3), 317-333.

Mukherjee, N., Hardjono, J. \& Carriere, E. (2002). People poverty and livelihoods: Links for sustainable poverty reduction in Indonesia. Jakarta: The World Bank.

Muslim, F. (2002). Madrashah (Islamic schools) education in Indonesia: Opportunities and challenges. Jakarta: UNESCO.

Myrsiades, L. (2001). Looking to lead: A case study in designing executive education from the inside. The Journal of Management Development, 20(9), 795-812.

O’Rourke, R. (1998). The learning journal: From chaos to coherence. Assessment and Evaluation in Higher Education, 23(4), 403-414.

Patton, M. Q. (2002). Qualitative research and evaluation methods ( $3^{\text {rd }}$ ed.). Thousand Oaks, CA: Sage Publications.

Pounder, J. S. (2003). Employing transformational leadership to enhance the quality of management development instruction. The Journal of Management Development, 22(1), 6-13.

Rosier, G. (2002). Using reflective reports to improve the case method. Journal of Management Development, 21(8), 589-597.

SAGRIC. (2003). Inception report: JFPR: Community based basic education for the poor: Package B: Social preparation and capacity building. Jakarta: Asian Development Bank.

Schostak, J. P. (2002). Understanding, designing and conducting qualitative research in education: Framing the project. Buckingham: Open University Press.

Seidman, I. (1998). Interviewing as qualitative research: A guide for researchers in education and the social sciences $\left(2^{\text {nd }}\right.$ ed.). New York: Teachers College Press.

Smith, H. J. (1997). Adventuring in Indonesia: Java, Bali, Sumatra, Kalimantan, Sulawesi, Nusa Tenggara, Maluku, Irian Jaya. San Francisco: Sierra Club Books.

Sugarno, O. A. (2004). Efficacy of role-playing pedagogy in training leaders: Some reflections. Journal of Management Development, 23(4), 355-371.

UNESCO-UNICEF. (2003). Creating learning communities for children: Improving primary schools through school based management and community participation. Jakarta: Government of Indonesia.

Waddock, S. A. (1999). Linking community and spirit: A commentary and some propositions. Journal of Organizational Change Management, 12(4), 332-344.

Wiersma, W. (2000). Research methods in education: An introduction. Boston: Allyn and Bacon.

Woolfe, L. (2002). Bible on leadership: From Moses to Matthew: Management lessons for contemporary leaders. New York: AMACOM.

The World Bank. (2003). Education in Indonesia: Managing the transition to decentralization. Jakarta: Government of Indonesia.

The World Bank. (2005). Education in Indonesia: Managing the transition to decentralization. Washington, DC: East Asia and Pacific Region Human Development Sector Unit.

Yin, R. K. (2003) Case study research: Design and methods ( $3^{\text {rd }}$ ed.). Thousand Oaks, CA: Sage Publications. 


\section{Biography}

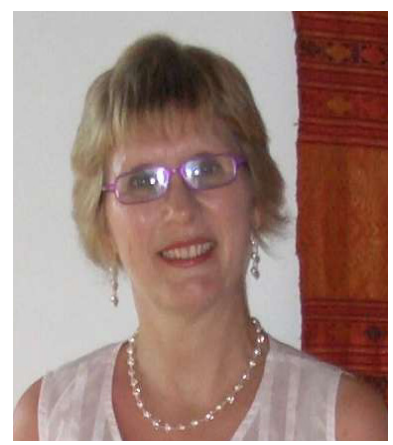

Alison Atwell is an Australian Educational Consultant with thirty years experience in education in Australia and Indonesia. Her current focus is in school leadership, and school counselling. She has been based in Jakarta since 2002 but has previously lived on the Indonesian island of Sulawesi for six years. Since 2002 she has worked for a range of Aid organizations throughout Indonesia including the United States Agency for International Development (USAID), The World Bank (WB) and the Asian Development Bank(ADB). She is currently a Doctor of Education student with the University of Southern Queensland, Toowoomba. 